\title{
Os periódicos polono-brasileiros: historiografia, fontes temas de pesquisa
}

The Polish-Brazilian journals: historiography, sources and research themes

Rhuan Targino Zaleski Trindade* rhuan.trindade@hotmail.com

Resumo: A comunidade polonesa do Brasil tem suas raízes no último quartel do século XIX, inserida no bojo da imigração europeia massiva. Ao longo da sua instalação e desenvolvimento no país de acolhida criou espaços de sociabilidade e uma série de instituições focadas na vida cultural polonesa, dentre elas, os periódicos. Ainda que mais tardiamente em relação a outros grupos étnicos, desde finais do século XIX até o advento de políticas nacionalistas brasileiras na década de 1930, os poloneses produziram diversos periódicos focados nos mais diferentes temas que circularam pelo sudeste e sul do Brasil. Alguns foram mais efêmeros e outros tiveram uma perenidade que, entre intervalos, chegaram aos nossos dias. Podemos identificar uma gama de um material muito rico, que permite uma série de digressões sobre a sociabilidade, economia, agricultura, religiosidade, disputas, entre outros assuntos relacionados à presença dos poloneses no Brasil. A importância numérica polonesa, especialmente no sul do país, não está, até então, refletida nos estudos acadêmicos e os periódicos polono-brasileiros são possibilidades de enfrentar essa questão. Ao propor uma reflexão acerca desta fonte, investigamos os usos atinentes ao estudo dos periódicos, examinando as possibilidades de análises e o potencial deste material para a pesquisa histórica, embasado em trabalhos que usaram estas fontes e estudos sobre imprensa e imigração.

Palavras-Chave: imigração polonesa, imprensa, fontes

Abstract: The Polish community in Brazil has its roots in the last quarter of the nineteenth century, set in the midst of massive European immigration. Throughout its installation and development in the host country, it created social spaces and a number of institutions focused on Polish cultural life, among them, the journals. Although later in relation to other ethnic groups, from the late nineteenth century until the advent of Brazilian nationalist policies in the 1930 decade, the Poles produced several journals focused on various themes and circling the southeast and south of Brazil. Some were more ephemeral and others with a continuity that between intervals, came to our days. We can identify a range of very rich material, which allows a number of digressions on sociability, economics, agriculture, religion, disputes and other matters related to the Polish presence in Brazil. The Polish numerical importance, especially in the country's South, is not so far reflected in academic studies and the Polish-Brazilian journals are possibilities to address this issue. By proposing a reflection on this source, we investigate the uses relating to the study of periodicals, examining the possibilities for analysis and the potential of this material for historical research, based on works that used these sources and studies on press and immigration.

Keywords: Polish immigration, press, sources

*Doutorando pela Universidade Federal do Paraná (UFPR). Agência financiadora CAPES. 


\section{Introdução}

A comunidade polonesa do Brasil tem suas raízes no último quartel do século XIX, no bojo da imigração massiva europeia para a América do Sul. Ao longo da sua instalação e desenvolvimento na sociedade de acolhida os poloneses criaram espaços de sociabilidade e uma série de instituições focadas na vida cultural polonesa, dentre elas, os periódicos.

A importância numérica polonesa, especialmente no sul do país, não está, até então, refletida no âmbito da pesquisa acadêmica. Para exemplificar a necessidade de estudos, em um evento sobre imprensa e imigração em 2002 ${ }^{1}$, apesar dos múltiplos trabalhos apresentados, não há registro de nenhum sobre os poloneses e, mesmo hoje, não existem trabalhos acadêmicos que tratem dos periódicos deste grupo étnico. A historiografia tem feito menção à relativamente pequena produção sobre imigração polonesa, sempre comparada à extensa abordagem sobre imigração italiana e alemã. Este enfoque comparativo foi questionado por Regina Weber e Thaís Wenczenovicz (2012) que apontaram uma série de argumentos sobre as dificuldades de se trabalhar com a temática da comunidade polonesa, bem como buscaram explicar o pequeno desenvolvimento desta no âmbito acadêmico.

Uma das maneiras de enfrentar essa questão é através da utilização dos periódicos polono-brasileiros que foram criados pela comunidade polonesa em diferentes locais de colonização, em especial na região sul do Brasil. Os periódicos como fonte para a escrita da História, notadamente desde a terceira geração dos Annales, sofreram uma revalorização como documento histórico, sua abordagem então permite diversas possibilidades de investigação.

Apesar de ter se desenvolvido tardiamente em relação a outros grupos étnicos, desde os anos finais do século XIX até o advento de políticas nacionalistas brasileiras nos anos 1930, os poloneses produziram diversos impressos com relativa periodicidade focados nos mais diferentes temas e circulando pelo sudeste e sul do Brasil. Tais impressos são ricos em informações sobre os poloneses, desde notícias e relatos cotidianos das colônias e dos habitantes das cidades, sobre o Brasil, a Polônia e os estados em que existem comunidades polonesas; até a publicação de artigos de intelectuais de destaque no mundo acadêmico, publicação de opiniões, propagandas, transcrições de cartas e outros textos.

Existiam também periódicos com características particulares, como jornais e folhetos partidários, literários, agrícolas, satíricos, humorísticos, educacionais, religiosos voltados à Igreja Católica, outros de instituições estatais polonesas, bem como de associações culturais étnicas. Este material, portanto, permite várias apreciações sobre a sociabilidade, economia, agricultura, religiosidade, disputas, entre outros assuntos relacionados à presença dos poloneses no Brasil.

Estabelecemos um objetivo propositivo e não analisamos em profundidade um jornal específico, mas pretendemos traçar um panorama da imprensa polonesa no Brasil entre o final do XIX e o Estado Novo. Primeiramente refletindo sobre a inserção dos poloneses na equação imprensa e imigração; depois pretendemos abordar alguns jornais poloneses divididos pelos estados em que foram criados, esses jornais têm características mais amplas, sendo voltados também para notícias e publicação de artigos; por fim, será feita uma análise mais focada em periódicos com temas específicos. Assim, através desta apreciação, analisamos o potencial dos jornais polono-brasileiros como fonte para a escrita da história da imigração polonesa no Brasil e suas relações com o desenvolvimento desse grupo étnico no sul do país.

\footnotetext{
${ }^{1}$ Seminário Nacional Imigração e Imprensa ocorrido em São Leopoldo.
} 
Os periódicos poloneses: alguns apontamentos iniciais sobre imprensa e imigração

As instituições são importantes para os seres humanos, pois permitem a realização de atividades que não lhe são fornecidas pelo seu equipamento biológico (BERGER, LUCKMAN, 1973). Nesse sentido, determinado grupo social pode se organizar e fundar instituições para diferentes fins. Essas instituições podem se tornar étnicas ao receberem significados simbólicos específicos ligados à etnicidade. Para tal empreendimento existe a necessidade de uma classe média, ou seja, um grupo com disponibilidade de tempo e recursos capazes de criar e manter ações de afirmação étnica:

el momento en que se percibe la presencia de una clase media es señal de una mayor adaptación del grupo a la sociedad. La existencia de un relativo número de miembros de clase media es fundamental para mantener determinados modos de afirmación étnica, como por ejemplo, publicaciones regulares o asociaciones recreativas o educativas con sede propia, las que corporizan su existencia y proveen de un lugar especifico para variadas actividades. (WEBER, 2009, p. 29).

Segundo Barth, a definição de um grupo étnico se dá na interação social, geradora de processos de inclusão e exclusão, tendo como resultado a delimitação de fronteiras. Para a constituição destas, são escolhidos ou modificados traços que servem como elementos de distinção e de diferenciação social (STREIFF; POUTIGNAT, 1998), características compartilhadas, estabelecidas como símbolos identitários, as quais instituem a crença em uma origem comum, podendo ser reforçadas e/ou modificadas. Esta origem é buscada no passado a fim de estabelecer uma identidade de grupo, no caso, com predicados étnicos.

Um exemplo possível de instituição com atributos étnicos são os periódicos, isto é, jornais, almanaques, calendários, revistas, entre outros tipos de ma- teriais que circulam através de e para um grupo étnico específico. No Brasil, a configuração de fronteiras étnicas, as quais podem ter periódicos como instituições, de uma maneira ou de outra, está marcada pela imigração, em especial, a europeia de meados do século XIX até início do XX.

Como coloca Klug (2004), a imprensa é um "símbolo da imigração". Nelson Werneck Sodré (1983), em História da imprensa no Brasil, assinala o surgimento de periódicos de imigrantes já no final do século XIX. Alemães, italianos, portugueses e mesmo japoneses e imigrantes do Oriente Médio (OLIVEIRA, 2004) procuraram criar impressos com diferentes objetivos:

à função de revivificador das raizes deixadas no além-mar deviam se agregar outras no periódico imigrantista, como as de órgão assistencialista, de defensor da respeitabilidade, de formação moral, de divulgador cultural, de fórum de debates e, o que parece não ter sido a tônica da totalidade dos jornais e revistas imigrantistas que circularam no Brasil, de denúncia e repúdio às desigualdades sociais existentes na própria colônia (OLIVEIRA, 2004, p. 147).

Entre as características principais estão o uso da língua materna e de um caráter balizador étnico capaz de estimular a coesão social, através da utilização dos periódicos pelas lideranças étnicas de cada grupo. A imprensa imigrante era, portanto, aquela produzida por um grupo étnico específico (oriundo de um processo de imigração) e dirigida para o próprio grupo, em geral, na língua materna.

Os poloneses podem ser incluídos nesta equação dos periódicos e imigrantes. Ainda que considerada pequena (POTOPOWICZ, 1936) se comparada à produção de jornais, anuários e revistas da colonização alemã (DREHER, 2004; GERTZ, 2004) e italiana, a imprensa polonesa no Brasil foi ativa. $\mathrm{O}$ ex-cônsul da Polônia no Brasil, Kazimierz Gluchowski, que escreveu 
em 1927 (publicado em português em 2005), demonstrou a existência de vários periódicos, contudo, muitos sendo efêmeros e permeados por disputas políticas as quais levavam, de acordo com o autor, ao desinteresse do público leitor.

Uma das razões da menor produção literária polonesa em relação aos seus congêneres alemães e italianos é o fato de que a elite letrada da Polônia não emigrou para o Brasil, mas para outras nações (o que definiria o caráter predominantemente agrário da colonização polonesa no Brasil), conforme apontam Gardolinski (1956) e Wachowicz (1974). Contudo, apesar de não constituir a maioria dos imigrantes, vários intelectuais poloneses imigraram temporariamente ou definitivamente ao longo dos séculos XIX e XX. Muitos dos quais se dedicaram à criação de periódicos. Destaque especial aos padres católicos emigrados, os quais eram responsáveis pela organização não apenas religiosaespiritual da comunidade, mas social e cultural. Sendo aqueles que se preocupavam com a criação e manutenção de jornais e outros materiais de divulgação religiosa (panfletos, folhetos, etc.).

Vários intelectuais laicos também foram encarregados da produção e divulgação de periódicos, muitos dos quais entraram em atritos com o elemento clerical, em disputas que tiveram reminiscências importantes nas páginas dos jornais polono-brasileiros. Uma característica daqueles jornais é justamente o fato de que se tornavam espaços de debates acirrados e disputas. As disputas religiosas e entre clericais e laicos eram parte significativa da imprensa imigratória étnica polonesa, assim como na alemã (DREHER, 2004).

Em Curitiba, na visão do historiador vicentino ${ }^{2}$ Piton (1971, p. 82), o final da primeira década do sécu- lo XX foi um período de "batalha pela hegemonia na colônia polonesa", onde já existia uma atividade dos padres desde os primórdios da imigração, que são confrontadas posteriormente pela vinda de funcionários do governo polonês e intelectuais laicos, que eram chamados "progressistas" e anticlericais. Segundo Piton (1971), tais debates levaram muitos escritores a melhorarem suas redações e tornarem-se literatos de destaque na comunidade.

A título de sistematização, consideramos neste trabalho a imprensa polono-brasileira como composta por periódicos escritos em polonês no Brasil desde os primeiros anos da colonização polonesa até o Estado Novo. Com as políticas nacionalistas estadonovistas, a imprensa polonesa acabou e somente ressurgiu após 1945 sobre outros vieses, os quais merecem um trabalho separado. Não incluiremos no texto os almanaques e anuários, que são fontes relevantes, mas que igualmente devem ser analisados de maneira independente numa oportunidade futura.

Entre o final do século XIX e o ano de 1938 foram criados mais de cem impressos periódicos em língua polonesa no Brasil, não sendo possível, nem desejoso, trazer a faina todos aqueles escritos, mas sim, alguns dos mais relevantes, seja pela duração, temática ou expressividade da tiragem. Todos esses elementos influem para refletir a dinamicidade e relativa importância da imprensa polono-brasileira.

\section{Os periódicos poloneses no Brasil}

Gluchowski (2005) Piton (1971) são as fontes mais importantes sobre os periódicos polonobrasileiros, apresentando várias informações e sistematizações. Gluchowski, primeiro cônsul da Polônia em

\footnotetext{
${ }^{2}$ Congregação religiosa formada na França, mas que preocupou-se no atendimento espiritual e também secular dos imigrantes poloneses no sul do Brasil, especialmente com a instauração em 1903 da Vice-Província Vicentina em Curitiba, que respondia à Cracóvia. Muitos padres vicentinos eram poloneses.
} 
Curitiba, escreveu em 1927 e seus dados são fontes preciosas ao que ele afirma ser a "imprensa polonesa". O padre vicentino Jan Piton, escreveu no momento da comemoração do centenário da imigração polonesa no Paraná (1971), listando vários periódicos seguido de uma breve descrição. A estes autores, somamos a análise de outros textos e de nossas próprias pesquisas com alguns dos periódicos sobre os quais discorremos neste artigo.

Primeiramente, entendemos os jornais como fonte documental capaz de enunciar discursos e expressões, intervindo nos processos e acontecimentos históricos e sendo permeados pelas questões de seu tempo, na medida em que são produtos da sociedade em que estavam inseridos e que os produziu. Ademais, os periódicos são atravessados por escolhas do ponto de vista político, mas também econômico, visando, em geral, o lucro, para além de conseguir adeptos, moldar comportamentos ou despertar consciências (CAPELATO, 1988; DE LUCA, 2010).

As escolhas subjetivas são feitas por diferentes motivações de um determinado grupo, conformadas num contexto de produção específico, as quais levam a definição daquilo que deve ser divulgado no periódico e para quem estão voltadas as informações. Neste ínterim, há jornais que, por exemplo, podem estar vinculados diretamente a partidos políticos ou à Igreja católica e dirigidos a um público específico mais restrito. Em contraposição, outros se colocam como empresas que produziriam uma divulgação "imparcial" (ainda que a seleção do que deve ser publicado não seja neutra) dos acontecimentos e são voltados a um público mais ampliado.
A partir destes pressupostos, devemos ter em conta que do ponto de vista metodológico, como Elmir (2007, p. 14) nos elucida, existem duas maneiras de ler o jornal: uma "aparentemente mais simples, consiste em tomá-lo (1) como fonte de informação". Outra, "aparentemente mais complexa, faz dele (2) objeto intelectual da pesquisa". Desta forma, se deve proceder com a crítica da fonte, examinando sua carga seletiva e subjetiva.

É significativo observar o que o jornal está elegendo como importante, quais as notícias destacadas e consequentemente, aquelas silenciadas. Verificar os editoriais é um bom método para identificarmos o posicionamento daqueles que escrevem o periódico e sua apreciação em relação a assuntos específicos.

Tendo estes aspectos metodológicos em vista, um dado que deve ser levado em consideração ao tratarmos dos jornais polono-brasileiros é o fato de que até 1918, enquanto a Polônia não existia como estado independente ${ }^{3}$, a "imprensa polonesa" local estava muito interessada nos assuntos poloneses, isto é, na recuperação da independência e na política europeia. Após 1918, voltou-se para os assuntos locais da colônia e a política brasileira (GLUCHOWSKI, 2005). Além disso, não podemos esquecer da importância das disputas entre clericais $\mathrm{x}$ anticlericais que eram transpostas para as páginas dos periódicos, sendo assunto constante e inclusive uma referência para a criação de jornais oponentes.

Com base nestas observações, o estado brasileiro que recebeu a maior leva dos imigrantes poloneses foi o Paraná. Curitiba, sua capital, era circundada por uma grinalda de colônias daquele grupo imigratório, bem como recebia vários intelectuais da Polônia e abria

\footnotetext{
${ }^{3}$ De 1795, após a tripartição até 1918 com a volta ao mapa europeu, a Polônia não existia enquanto estado independente. Seu território esteve dividido entre os Impérios Alemão, Áustro-Húngaro e Russo.
} 
espaço para surgimento de uma classe média e um segmento urbano de comerciantes, profissionais liberais, professores, políticos e industriais poloneses e descendentes. Não é, portanto, surpreendente, que seja Curitiba e o Paraná o principal centro de produção de jornais, calendários, revistas e outros periódicos da comunidade polonesa.

O primeiro jornal escrito em polonês no Brasil é de 1892, o Gazeta Polska w Brazylii (Gazeta polonesa no Brasil), de Curitiba. Também foi o mais longevo, existindo sem interrupções até 1941. Chegou a ter tiragem de 4000 exemplares e marcou as disputas pela colônia polonesa, trocando de donos várias vezes: desde intelectuais progressistas até padres, mas manteve ao longo do tempo uma proximidade com a Igreja Católica.

No final do século XIX, houve a criação de jornais em oposição ao Gazeta, como o Kurier Paranski (O mensageiro paranaense 1897-1898), que era editado em Curitiba e proveniente da cidade polonesa de Lwów com tiragem de 300 exemplares. Outros são o Prawda (A Verdade 1900-1901) e o semanário Polak w Brazylii (O polonês no Brasil 1905-1920), ambos de Curitiba. Este último era considerado "progressista e anticlerical", chegando a 1500 exemplares de tiragem. O Polak w Brazylii e o Gazeta Polska travaram uma disputa por vários anos e em ambos os jornais aparecem críticas mútuas.

Em 1920, o Polak w Brazylii é assumido pelos missionários vicentinos e ressurge, naquele mesmo ano, com o nome Lud (O Povo), mudando radicalmente de orientação para uma posição clerical e conservadora. $\mathrm{O}$ Lud era publicado quinzenalmente a partir de 1930, tinha tiragem chegando a 4 mil exemplares e 25 mil lei- tores $^{4}$ nos estados do Paraná, Santa Catarina, Rio Grande do Sul, São Paulo, Minas Gerais e também na Argentina e no Uruguai (POTOPOWICZ, 1936, p. 209).

O jornal $L u d$, que continuou suas publicações até $1940^{5}$, é sem dúvida uma das fontes valiosas para estudar a comunidade polonesa, estando muito bem preservado no Acervo dos padres vicentinos em Curitiba e passa recentemente por um processo de digitalização através de um projeto da Universidade de Varsóvia.

$\mathrm{Na}$ capital paranaense outros periódicos podem ser destacados: Emigrant Polski w Paranie (O emigrante polonês no Paraná 1909), que propagandeava a vinda e concentração dos imigrantes poloneses no Paraná; o mensário católico vicentino Przyjaciel Rodziny (O Amigo da Família, 1921-1935); o Nasze - ycie (Nossa Vida, 1922-1923), que tinha apoio do cônsul Gluchowski e de Edmundo Saporski, considerado "pai da imigração polonesa". Devido a colaboração destes dois intelectuais, o jornal foi considerado de caráter "progressista", preocupado com a "vida social, científica e artística da comunidade polonesa" (PITON, 1971, p. 90); Polska Prawda w Brazylii (A verdade polonesa no Brasil 1929-1941), semanário que apesar de ser considerado "católico", foi avaliado por Piton como “progressista com tendências radicais" (1971, p. 92); Nasza Praca (Nosso Trabalho 1933-1935), outro destacado jornal, com tiragem de cerca de 600 exemplares, era bimensal e depois mensal, sendo vinculado a diferentes associações e tendo vários suplementos que tratavam de educação, agricultura e esporte; Kultura (Cultura 1933-1938) vinculado à associação escolar Kultura, que abarcava as escolas "progressistas" e se interessava por problemas culturais, educacionais, econômicos, entre outros.; Biuletyn Informacyjno Ins-

\footnotetext{
${ }^{4}$ Segundo texto do Jornal Gazeta do Povo de 11/01/2014, que contabiliza a leitura familiar e pública dos textos.

${ }^{5}$ Reaparece e permanece bilíngue no intercurso 1947-1999
} 
trukcyjnny (Boletim Informativo e Instrutivo, 19371938), com tiragem de 1000 exemplares, era vinculado ao Centralny Związek Polaków w Brazylii (União Central dos Poloneses no Brasil), órgão que pretendia agregar todas as associações polonesas do Brasil, sendo criado e patrocinado pelo consulado polonês de Curitiba.

Poderíamos mencionar ainda o Nasza Skółka (Nossa Escolinha, 1924-1935); Robotnik Paranski (O Trabalhador Paranaense, 1902-1903); Ogniwo (O Elo, 1913-1914); Świat Paranski (O Mundo Parananese, 1923-1925); Głos Paranski (A voz do Paraná, 1933); e Młody Paranczyk (O Jovem Paranaense, 1937-1938). Todos estes tiveram uma trajetória mais curta.

O mencionado Ogniwo era inicialmente de Ponta Grossa, mas migrou para Curitiba e deu origem ao Pobudka (O Estímulo, 1916-1918), considerado “progressista-esquerdista” (PITON, 1971, p. 87). Ambos, devido ao período de circulação, se dedicaram às notícias sobre a Primeira Guerra Mundial evidenciando os múltiplos lados pelos quais lutavam os poloneses, seja o Comitê de Paris de Paderewski, Haller e Dmowski, vinculado à Ententé ou então as Legiões de Pilsuds$\mathrm{ki}^{6}$, que lutavam no lado Áustro-Húngaro. Finalmente, o Pobudka foi substituído pelo Świt (a Aurora, 19181928), retornando a Curitiba em 1921 e vinculando-se à organização Kultura. Também foi editado em Ponta Grossa o mensário católico Siewca (O Semeador, 19331934). Ainda no Paraná, editado em Marechal Mallet, existiu de maneira efêmera o Człowiek Lesny (O Mateiro, 1916).

No Rio Grande do Sul, segunda maior colônia polonesa no Brasil, também existiram publicações de periódicos poloneses. O mais importante foi o Odrodze- nie (O Renascimento, 1930-1934) impresso pela Tipografia Polonesa em Porto Alegre com 1000 exemplares de tiragem. Segundo um dos colaboradores da época: "no mais longínquo recanto, na mais pobre casinha, tal escrito [Odrodzenie] chega (ciśnie) lá”, sendo recebido em diferentes colônias polonesas no Rio Grande do Sul. Tinha vários suplementos: sobre educação, agricultura, notícias das colônias etc.

Destacamos ainda no Rio Grande do Sul o Kolonista (O colono, 1909-1910) e o Kolonista Polski (O colono polonês), ambos de Ijuí. Em Guarani das Missões, maior colônia polonesa do estado, existia o Tygodnik Związkowy (Semanário das Associações, 19161917), que acabou, segundo Piton (1971), censurado por questões políticas. Em Rio Grande saiu um número chamado Naprzód (Avante, 1905) da Sociedade Águia Branca. Existiram também o Echo Polskie (Eco Polonês, 1927-1929) e o Biuletyn Informacyjny (Boletim Informativo, 1938) ambos editados em Porto Alegre pela Federação das Sociedades Polonesas do Rio Grande do Sul.

Premente é destacar que os jornais de Curitiba circulavam pelas colônias polonesas do Rio Grande do Sul e Santa Catarina, bem como eram lidos em alguns outros estados (ou países), onde existia presença de poloneses, caso exemplificado pelo $L u d$, que encontramos em arquivos privados de Porto Alegre e Guarani das Missões.

Paradoxalmente, em São Paulo, especialmente na capital, que não era uma das grandes colônias polonesas em termos populacionais, há um grande número de periódicos ainda que, na sua maioria, de curta circulação. O mais antigo foi o Dzwoń Polski (O Sino polo-

\footnotetext{
${ }^{6}$ Durante a Primeira Guerra Mundial a Polônia, então ocupada, envolveu-se dos dois lados do conflito. De um lado tropas lutavam pela Alemanha, do outro pelos russos e ainda existiam tropas polonesas lutando com os franceses, chamado de Exército Azul. Confrontando poloneses contra poloneses. No entanto, a que mais se destacou foram as Legiões Polonesas comandadas por Pilsudski, que lutaram de forma mais ou menos independente do lado Áustro-Húngaro contra a ocupação da porção russa, que detinha a maior parte do que fora o estado polonês.
} 
nês 1907-1908), criado pelos cafeicultores paulistas propagandeando a migração de poloneses para os cafezais de São Paulo, uma vez que a maioria da população imigrante polonesa preferiu adquirir terras nos estados sulinos ao invés de servir de mão de obra para a produção cafeeira paulista.

Entre 1929-1930 circulou o Kurier Polski (O Correio Polonês), que tinha como secretário José Issakowicz, importante redator do Odrodzenie e de outros periódicos no período. Podemos citar ainda o Ilustrowany Informator Polski w Brazylii (Informativo Ilustrado Polonês no Brasil 1931) e seu substituto, o Nowiny Ilustrowane (Notícias Ilustradas 1932), ambos com poucos números e editados na cidade de São Paulo. No âmbito religioso, em 1935, circulou o Związek Polsko Katolicki (União Polono-Católica), que trazia notícias da Igreja.

Em geral, nesta primeira parte foram mencionados periódicos ligados à Igreja Católica ou rivais dela, os quais privilegiavam notícias cotidianas da comunidade polonesa, além de destaques para os seus estados específicos, o Brasil, a Polônia e o Mundo. Eram de caráter propagandístico e informativo, voltados especificamente para um grupo étnico em particular, tinham, em geral, posicionamentos que claramente não se pretendiam neutros ou imparciais, mas que marcavam pontos de vista alicerçados nas opiniões dos órgãos que os financiavam, dos seus donos e redatores.

Piton, na condição de padre, ao referir-se aos jornais, muitas vezes caracteriza os periódicos como "progressistas", "esquerdistas", "radicais”, mas não faz o mesmo com aqueles vinculados à Igreja, ao contrário de Gluchowski, quem denominava, eventualmente, determinados jornais como "clericais".

\section{O Lud de Curitiba e o Odrodzenie de Porto Ale-} gre, que analisamos mais detidamente, em especial para os anos 1930, são exemplos que trazem à tona esta disputa. O primeiro, vinculado à Igreja, traz notícias diversas, porém, é possível observar o quanto criticam as contendas com os anticlericais, estes sendo considerados responsáveis pela "desorganização" da comunidade, criando, segundo alguns padres, uma desconfiança com os "instrutores, professores, vindos da Polônia, e com verdadeira tristeza deve-se dizer também com relação a Polônia. A confusão, que foi introduzida aqui na vida social polonesa, é difícil eliminar e desenraizar o mal". 7

Já o segundo, apesar de se apregoar como "apartidário", publica um enfoque muito semelhante, tendo artigos escritos por padres e seus "aliados" leigos. Muitos textos criticam os funcionários enviados da Polônia, que procurariam transformar as instituições locais em sociedades laicas e sob a tutela do estado polonês. Como assevera um articulista, a "Colônia [polonesa] possui pessoas mais educadas, mais patriotas do que eles os senhores instrutores". 8

A própria existência de periódicos rivais, como apontamos acima, denota as diferenças "ideológicas" dentro da colônia polonesa que, como qualquer grupo (étnico), apesar da noção e intenção de coesão, tem divisões e disputas em torno de lideranças específicas (neste caso, do clero ou laicas). Importante destacar que estes jornais permitem uma análise das comunidades polonesas, sua intervenção na sociedade englobante e o

\footnotetext{
${ }^{7}$ Tradução: Lud, 11 de abril de 1934. Cartas para a argentina: Pe. Jan Wislinski Listy z Argentyny. ,instruktorów oświatowych, nauczycieli przybyłych z Polski, a z prawdziwym smutkiem powiedzieć trzeba, także i do Polski. Zamętu, który tutaj wprowadzano w życie społeczne polskie, dotąd usunąć nie podobna a zła wykorzenić".

${ }^{8}$ Tradução: Odrodzenie de 9 de julho de 1933, Franciszek Karnikowski: Kolonja posiada ludzi wyżej wykształconych, większych patrjotów niż sami pp. Instruktorzy
} 
processo de colonização. Ademais, os periódicos trazem muitos dados sobre as colônias, no âmbito rural e urbano, apontando números de imigrantes e descendentes, as condições de assentamento e a adaptação dos poloneses ao espaço receptor.

Os artigos de intelectuais que eram publicados nos periódicos permitem analisar também diversos aspectos como a educação, ciência, religião, entre outros assuntos que eram recorrentes nos espaços de sociabilidade poloneses constituídos ao longo da sua presença no Brasil.

\section{Os periódicos e as suas temáticas:}

trabalhadores, esporte, educação, agricultura, humor e religião

A colonização polonesa proporcionou a criação de diferentes instituições étnicas, as quais colocaram em movimento a comunidade e permitiram, como consequência, a busca de uma coesão social e a criação e conformação de uma identidade étnica polonesa na terra de adoção, a fim de constituir um grupo étnico mais ou menos organizado. Além disso, são exemplos da adaptação e modificação da sociedade receptora pelos imigrantes, conformando sociabilidades étnicas particulares.

Sociedades culturais, esportivas, escolares, cursos de professores, associações agrícolas, cooperativas, associações de trabalhadores urbanos, ideias para criação de um banco polonês, até a possibilidade de conquista territorial para a Polônia, são exemplos de atividades conformadas pelos poloneses entre o final do século XIX e as primeiras décadas do século XX. Os periódicos se desenvolveram pari passu a estes movimentos e/ou vinculados a eles. Assim, nesta seção desenvolvemos a análise de alguns jornais particularmente ati- nentes às atividades específicas da comunidade polonesa, diferentemente dos periódicos de caráter mais geral descritos acima.

Um assunto recorrente diz respeito ao âmbito dos trabalhadores urbanos poloneses, neste caso, Curitiba, no Paraná, novamente tem proeminência. Além do citado Robotnik Parański (O trabalhador paranaense), que como o nome remete, estava voltado ao trabalho polonês naquele estado, entre 1902-1903, desenvolvese também o Naród (A Nação 1908-1909) que, além de criticar todos os outros periódicos curitibanos poloneses, tinha, de acordo com Piton", viés "esquerdista". Outro interessante jornal foi o Proletariat Polski w Ameryce Poludniowej (O proletariado polonês na América do Sul 1921) da Associação Central dos Poloneses trabalhadores de fábricas de São Paulo. De acordo com Piton, este jornal fez parte de uma "experiência comunista" (PITON, 1971) que ficou marcada pelo polonês mal escrito e pela efemeridade (GLUCHOWSKI, 2005), tendo sido editado somente um número.

As associações esportivas também marcaram presença nos periódicos escritos em polonês. Em 1922, em Curitiba, circulou alguns números com 500 exemplares de tiragem do Sportowiec Polski (O Desportista polonês), vinculado às sociedades esportivas Harcerz (O Batedor) e Junak, em geral, tendo o apoio de indivíduos enviados da Polônia. Em 1931, O Junak (nome dado ao Towarzystwo Wychowania Fizycznego Junak ou em português: Sociedade de Educação Física Junak) lança um jornal de mesmo nome editado também em português. Por último, em Porto Alegre, a Sociedade Sokól (Falcão) entre 1929-1930 teve como órgão o periódico Sportowiec (O Desportista).

\footnotetext{
${ }^{9}$ Para o padre escrevendo nos anos 1970 e ponderando a expressão, podia significar desde um ponto de vista menos conservador e clerical, até um posicionamento vinculado politicamente à esquerda.
} 
É interessante notar, conforme Oliveira, que a luta pela independência da Polônia e os vínculos com o nacionalismo são importantes, inicialmente, para a configuração das sociedades esportivas:

Percebe-se assim a estreita relação entre ginástica (ou esporte) e o processo de independência vivido em território polonês. As associações e sociedades criadas em Curitiba cumpriam assim um objetivo vindo de longe, vindo de fora. Ao contrário da representação nacional, que tratava os imigrantes como apenas estrangeiros em lento processo de assimilação, para estes, o Brasil, em especial, o Paraná, era de certa forma um trampolim (no sentido figurado e não esportivo do termo) para uma ação política no sentido estrito do termo. O esporte, assim, não se desvinculava da politica, nem as tradições culturais da nação. A moderna idéia de atleta, por exemplo, por certo não existia. Antes disso, o esporte parecia ser uma forma de educação, e nisso, se combinava ao espírito da época que via nesta última uma forma de "civismo nacional" $e$ de construção do Estado, e não de transmissão de conhecimentos. (2008, p. $5)$.

Aos poucos, as atividades esportivas perdem seu caráter bélico para se limitarem à capacidade de integração das comunidades de imigrantes. As associações esportivas tem um papel na divulgação da atividade esportiva, na inclusão das crianças e mulheres neste espaço e na popularização do esporte (OLIVEIRA, 2008). Junto às escolas polonesas, estas sociedades são importantes na conformação do grupo étnico.

Gardolinski (1974) e Wachowicz (2002 [1970]) são dois dos autores que sobressaem a presença de escolas polonesas nos estados do Sul, notadamente no Paraná e Rio Grande do Sul. Em ambos se desenvolveu, poderíamos dizer, uma rede de "ensino polonês", desde pequenas escolas nas linhas e picadas das colônias, até centros de formação médio e técnico, bem co- mo de professores em Marechal Mallet - PR e Guarani das Missões - RS. Existe, inclusive, uma literatura recente que trata do assunto: Renk (2009) no Paraná e Malikoski (2014) e Trindade (2015) para o Rio Grande do Sul.

É graças a existência do ensino em polonês ou também bilíngue que podemos imaginar o quanto os periódicos dispunham de um público leitor razoável. Primeiro, até 1938, as escolas polonesas - as quais ensinavam na língua materna ou com ensino bilíngue - no Rio Grande do Sul, funcionaram praticamente sem restrições e até com incentivos dos poderes públicos especialmente no âmbito rural. No Paraná, a exigência do ensino do português é anterior, mas isto não excluiu o aprendizado do polonês. Ademais, neste estado se concentrava a maior quantidade de letrados e intelectuais poloneses do Brasil, possíveis consumidores e redatores de jornais.

As escolas também explicitaram as disputas pela colônia polonesa. Em 1920 e 1921 surgem duas entidades rivais: a Kultura (Cultura) e Oświata (Educação), a primeira uma associação de escolas laicas e a segunda, de escolas católicas. Muitas destas associações de ensino criaram periódicos, caso do jornal Kultura já supramencionado.

Outros periódicos educacionais eram o Tygodnik Polski (Semanário Polonês) de 1911; o Nasza Szkoła (Nossa Escola) pertencente a Associação dos Professores das Escolas Polonesas do Brasil entre 1924 -1935; editado pelo Centralny Związek Polaków w Brazylii (União Central dos Poloneses no Brasil) ${ }^{10} \mathrm{o}$ Gazeta Szkolna w Brazylii (Gazeta Escolar no Brasil 1935), todos estes periódicos concentrados em Curitiba. Além disso, havia suplementos para professores e estu-

\footnotetext{
${ }^{10}$ Em 1930, foi criada a União Central dos Poloneses, que se mantinha em contato com a União Mundial dos Poloneses no Estrangeiro, criada em Varsóvia. A CZP abrangia uma serei de instituições do âmbito educacional, esportivo e agrícola poloneses.
} 
dantes nos maiores jornais em circulação (Lud, Nasza Praca, Gazeta Polska, etc). Estes periódicos podem ser importantes para pensar a educação dos imigrantes e descendentes poloneses e, através deles, a conformação simbólica identitária grupal polonesa no Brasil.

Outro ponto importante que os periódicos trazem à tona é a agricultura. Klug (2004, p. 25), tratando da imprensa alemã, corrobora a importância dos jornais para a população rural dado que: "quase todos mantinham um suplemento literário e/ou com informações sobre agricultura". É justamente a população rural, que não era bilíngue, aquela que vai sofrer mais com as restrições à imprensa estrangeira durante o Estado Novo.

Não podemos esquecer que a maior parte da população polono-brasileira era de colonos. Os escritos dos jornais, em parte, voltaram-se para essa parcela da população. Muitos autores eram ativos na procura de melhorias das condições materiais e de vida dos colonos poloneses. Professores, padres, além de outros intelectuais incluindo membros representativos do Estado polonês, os "instrutores", foram indivíduos responsáveis por escrever artigos e criar periódicos, a fim de distribuir entre os camponeses letrados ou para serem lidos em público, com intuito de permitir a melhoria das técnicas, cultivos, métodos e resultados da produção agrícola.

Os jornais polônicos são muito interessantes para entender o desenvolvimento agrícola levado a cabo no período entre os colonos poloneses e merecem destaque neste trabalho. Estes jornais contavam com artigos de estudiosos, em geral, mas não somente, diletantes sobre a agricultura. Os textos eram voltados normalmente para os colonos, ou então, para as pessoas responsáveis por tentativas de inovação e desenvolvimento rural no seio da comunidade, papel que era exercido por diferentes sujeitos, podendo muitas vezes os professores da região ocuparem tais cargos. A lingua- gem dos textos não era exatamente acessível para a maioria da população, o que nos leva a pensar que havia um filtro feito através da leitura pública ou do repasse das informações por meio de intermediários.

Eram escritos artigos sobre novos produtos, sobre pecuária, métodos de cultivos de plantas já conhecidas pelos colonos, excertos sobre combate às pragas como as lagartas e os gafanhotos, sobre o calendário agrícola, solos, as escolas/círculos agrícolas, pastagens, entre muitos outros assuntos que faziam parte do universo mental e de trabalho do "camponês polonês". Lud, Nasza Praca, Prawda Polska w Brazylii, entre outros, tinham suplementos e espaços destinados ao tópico agricultura com títulos como Rolnik (O Agricultor), comum em vários cadernos das publicações. Além disso, intelectuais e cientistas renomados como Ceslau Biezanko (reconhecido entomólogo e agrônomo polonês), publicavam artigos sobre agricultura e combate às pragas nos jornais. Tal cientista, enquanto esteve em Guarani das Missões, fez uso do periódico Odrodzenie e $L u d$ para difundir o cultivo da soja entre os colonos poloneses na década de 1930 (TRINDADE, 2015).

Outro tipo de periódico que destacamos são os humorísticos e satíricos. Desde o final do século XIX foram publicados este tipo de impressos. O Djablik Paranski (O diabinho paranaense) já em 1898 saía com 300 exemplares em Curitiba. Depois em 1902, na mesma cidade, são criados o Djablik (O Diabinho) e o Scierka (O Esfregão), ambos satirizando um ao outro. O primeiro foi concebido para fazer humor do Robotnik Parański, que então criou o segundo como forma de contrabalançar os ataques.

\section{Em 1919, em Ponta Grossa, aparece o Sowirzdr-} zal w Paranie (O traquinas no Paraná), considerado "progressista" por Gluchowski (2005), sendo defensor das políticas de Pilsudski na Polônia. Em 1921 o Osa (A vespa) circula por algum tempo. Em 1929, em Curi- 
tiba, é editado outro Djablik Paranski, tendo como redatores os pseudônimos X. Niekliei e Y. Nienozyce (Não cole e não recorte). $\mathrm{O}$ último periódico deste tipo foi $\mathrm{o}$ Djablik Brazylijski (O diabinho brasileiro) de 1932, também em Curitiba.

Por último, não podemos deixar de destacar a presença de "jornais religiosos", isto é, pertencentes ou vinculados à Igreja Católica através das congregações e seus padres. A religiosidade polonesa católica é fundamental para entender a vinculação étnica, ou melhor, a identidade étnica construída pelos poloneses no Brasil (GARDOLINSKI，1958; STAWINSKI，1975，WACHOWICZ, 1974). O fato é que, a presença da religião católica estaria incorporada à polonidade, tanto o sentimento nacional (TRINDADE, 2013) como o de pertença étnica, ou seja, à etnicidade polonesa. Na primeira parte do texto, citamos alguns dos jornais que tinham preponderância do elemento religioso, seja jornais propriamente das igrejas que publicavam notícias específicas das congregações ou paróquias, sejam os jornais mais amplos como o Lud ou o Odrodzenie, que tinham outros vieses, mas contavam com padres entre os redatores e articulistas. As instituições religiosas eram capazes de financiar os jornais e permitiam a publicação de diferentes notícias e artigos por seus colaboradores laicos, permitindo a circulação de informações dentro da comunidade polonesa.

Para finalizar, não pretendemos fazer uma exaustiva análise dos periódicos poloneses na periodização proposta, mas traçar um panorama do que podemos chamar de "imprensa polonesa" no Brasil dentro do contexto da imprensa imigrante e étnica. É importante notar que alguns destes jornais, boletins informativos, panfletos e pasquins mencionados não foram "periódicos" no sentido estrito da palavra, sendo às vezes lançado apenas um número ou existindo com uma regularidade bastante limitada. As disputas religiosas e as rivalidades entre os jornais são dados importantes também, que perfazem a tônica da imprensa imigratória étnica polonesa. A despeito destes pressupostos, ao preservar a língua polonesa para leitores especificamente deste grupo étnico, esta imprensa era fruto dos interesses poloneses e um instrumento de reificação e afirmação da sua identidade grupal étnica.

\section{Considerações finais}

A despeito de a maioria dos periódicos citados não ter passado de alguns poucos números ao longo de alguns meses, outros foram mais longevos e atravessaram décadas. Em 1938, em consequência do decreto de nacionalização, praticamente todas as publicações editadas no Brasil em línguas estrangeiras foram fechadas, algumas poucas permaneceram até 1941. Com a eclosão da Segunda Guerra Mundial o decreto de nacionalização foi suavizado. O governo permitia a publicação de boletins em polonês que dessem informações sobre a guerra ou que promovessem a ajuda organizada à Polônia e seus habitantes. Além disso, no pós-1945 alguns jornais ressurgem e outros novos são criados.

Através dos periódicos, diversos assuntos como esporte, cultura, humor, política, imigração, educação polonesa, associações, relações dos poloneses com a sociedade receptora, agricultura, meio ambiente, economia entre outros temas são possíveis de estudo. Seja utilizando-os como fontes de informação para os mais diferentes objetos que abordam ou silenciam, seja através de uma análise mais detida do posicionamento do periódico, estas são fontes primordiais para o estudo da imigração e colonização polonesa no Brasil.

O idioma tem sido a grande barreira a ser enfrentada. Há poucos historiadores e, quiçá, até mesmo leitores capacitados em polonês no Brasil atualmente. Algumas alternativas podem ser a utilização das publi- 
cações bilíngues, ainda que sejam relativamente poucas. Existe a possibilidade de convênios com universidades polonesas, onde cursos de ensino do português tem efetuado traduções. Por último, uma alternativa possível é o exemplo do estudo sobre o "Gazeta Polska w Brazylii”, no qual a abordagem central é sobre as imagens fornecidas pelo periódico buscando compreender como "o grupo polonês através das páginas da Gazeta Polaca expressou imagens identitárias particularizadas sobre seus hábitos e tradições sócio-culturais" de forma que "as imagens lidas enquanto indícios interpretativos do real, isto é, são reflexos da forma com que o grupo deseja se mostrar à sociedade e ao contexto em que estavam inseridos" (MOLAR; LAMB, 2011:2), portanto, outro meio possível de estudar estes periódi$\cos$.
A existência de uma educação polonesa que trazia o letramento para os agricultores e a leitura pública dos jornais, são fatores que demonstravam a existência de um público leitor importante. A circulação dos periódicos pelos três estados do sul do Brasil mais São Paulo, o grande número e variedade de jornais fundados e distribuídos, as tiragens significativas, são exemplos da dinamicidade e presença destas instituições no seio da sociedade polono-brasileira, o que torna o estudo destes documentos premente.

Em suma, os jornais são fontes através das quais se extrai o panorama de uma comunidade, apesar de seu fundo ideológico, permite captar o universo da sociedade em que está inserido (SANTOS, 2004). Assim, a imprensa polonesa no Brasil admite o estudo dos múltiplos aspectos do estabelecimento dos poloneses no Brasil e apropriar-se dos discursos identitários étnicos em diferentes âmbitos da sociedade.

\section{Referências bibliográficas}

BERGER, Peter L.; LUCKMANN, Thomas. A construção social da realidade. Tratado de sociologia do conhecimento. Vozes, Petrópolis, 1973.

CAPELATO, Maria Helena. Imprensa e História do Brasil. São Paulo: Contexto/EDUSP, 1988.

DREHER, Martin. A participação do imigrante na imprensa brasileira. In: DREHER, Martin; RAMBO, Arthur B.; TRAMONTINI, Marcos Justos (orgs.). Imigração e Imprensa. Porto Alegre: EST \& São Leopoldo: Instituto Histórico de São Leopoldo, 2004.

ELMIR, Cláudio Pereira. Uma Aventura com o Última Hora: O jornal e a pesquisa histórica. Conferência de abertura do Colóquio Fontes periódicas: imprensa política e cultural latino-americana do PPG da UFRGS, 2007.

GARDOLINSKI, Edmundo. Imigração e colonização polonesa. In: BECKER, Klaus (org.) Enciclopédia Riograndense. v. 5. Canoas: Regional, 1956.

1976.

. Escolas da colonização polonesa no Rio Grande do Sul. Porto Alegre: ESTSLB; Caxias do Sul: UCS,

GERTZ, René. Imprensa e imigração alemã. In: DREHER, Martin; RAMBO, Arthur B.; TRAMDNTIN, Marcos Justos (orgs.). Imigração e Imprensa. Porto Alegre: EST \& São Leopoldo: Instituto Histórico de São Leopoldo, 2004.

GLUCHOWSKI, Kazimierz. Os poloneses no Brasil: Subsídios para o problema da colonização polonesa no Brasil. Porto Alegre: Rodycz \& Ordakowski Editores, 2005.

KLUG, João. Imprensa e imigração alemã em Santa Catarina. In: DREHER, Martin, RAMBO, Arthur B., TRAMDNTIN, Marcos Justos (orgs.). Imigração e Imprensa. Porto Alegre: EST \& São Leopoldo: Instituto Histórico de São Leopoldo, 2004. 
LUCA, Tania Regina de. “A história dos, nos e por meio dos periódicos”. In: PINSKY, Carla Bassanezi (org.). Fontes Históricas. 2. ed. São Paulo: Contexto, 2010.

MALIKOSKI, Adriano. Escolas étnicas dos imigrantes poloneses no Rio Grande do Sul (1875-1939). Dissertação (mestrado), UCS, Caxias do Sul, 2014.

MOLAR, Jonathan de Oliveira, LAMB, Roberto Edgar. Imigração Polonesa: o sentimento identitário representado nas imagens da revista "Gazeta Polaca no Brasil”. História, imagem e narrativa, Rio de Janeiro, n. 12, abril, 2011. Disponível em: < http://www.historiaimagem.com.br/edicao12abril2011/imigracaopolonesa.pdf > Acessado em: 10 abr. 2012

OLIVEIRA, Carla Mary S. Imprensa e imigração na República Velha: A revista Lusitania e a colônia luso-carioca (1929-1934). Portuguese Studies Review, Lisboa, 2004.

OLIVEIRA, Márcio de. Sociedades esportivas e imigração: o caso dos poloneses em Curitiba, 1890-1940. In: $1^{\circ}$ Encontro da ALESDE, Curitiba, 2013. Anais do $1^{\circ}$ Encontro da ALESDE. Curitiba: Universidade Federal do Paraná, 2013.

PITON, Jan. Periódicos de Língua Polonesa no Brasil. In: Anais da Comunidade Brasileiro-Polonesa Volume III, Curitiba, 1971. p. 80-103.

POTOPOWICZ, Żabko. Historja Osadnictwa Polskiego w Brazylji. Varsóvia: Syndykat Emigracyjny Warszawa, 1936.

RENK, Valquiria Elita. Aprendi falar português na escola! O processo de nacionalização das escolas ucranianas e polonesas no Paraná. 2009. Tese (Doutorado), UFPR, Curitiba, 2009.

SANTOS, Roselys Izabel Correa dos. Imigração e imprensa italiana em Santa Catarina. In: DREHER, Martin; RAMBO, Arthur B.; TRAMDNTIN, Marcos Justos (orgs.). Imigração e Imprensa. Porto Alegre: EST \& São Leopoldo: Instituto Histórico de São Leopoldo, 2004.

SODRÉ, Nelson Werneck. História da imprensa no Brasil. São Paulo: Martins Fontes, 1983.

STREIFF, Jocelyne Fenart \& POUTIGNAT, Philippe. Teorias da etnicidade: São Paulo: Ed. UNESP, 1998.

TRINDADE, Rhuan T. Z. Um Cientista entre Colonos: Ceslau Biezanko, Educação, Associação Rural e o cultivo da Soja no Rio Grande do Sul no início da década de 1930. Dissertação (Mestrado), UFRGS, 2015.

. Polkość, Identidade e Etnicidade Polonesa: Conceitos em Construção. Passo Fundo, Anais do II Congresso Internacional de História Regional, 2013.

WACHOWICZ, Ruy Christovam. O camponês polonês no Brasil: raízes medievais da mentalidade emergente. Tese à Docência Livre, Curitiba, 1974.

. As escolas de colonização polonesa no Brasil. Curitiba: Champagnat, 2002.

WEBER, Regina. Grupos étnicos, estratégias étnicas. In: SIDEKUM, Antonio; GRÜTZMANN, Imgart; ARENDT, Isabel Cirstina (orgs.). Campos múltiplos. São Leopoldo: Oikos, 2008.

. Romances sobre inmigrantes y afirmación étnica. Acta lit., Concepción , n. 38, p. 27-42, 2009 . Disponível em: $<$ http://www.scielo.cl/scielo.php?script=sci_arttext\&pid=S0717-

68482009000100003\&lng=es\&nrm=iso>. Acessado em 11 out. 2016.

WEBER, Regina. \& WENCZENOVICZ, Thaís J. Historiografia da imigração polonesa: avaliação em perspectiva dos estudos sobre o Rio Grande do Sul. História UNISINOS. São Leopoldo, v. 16, 2012, p. 159-170. 